*Kokeza Nenad dipl.inž.maš

\title{
TEHNOLOGIJA ZAVARIVANJA \\ TRAVERZE
}

\section{Stručni rad / Professional paper}

Rad primljen / Paper received:

Jul 2015.

Ključne reči: TIG, zavarivanje, raznorodni čelici, metode ispitivanja zavarenog spoja

\section{Adresa autora / Author's address:}

* Lohr Bačka Topola d.o.o.

\section{APSTRAKT}

Predmet ove tehnologije je uputstvo za zavarivanje traverze. Osnovni materijal za izradu konstrukcije je čelik kvaliteta S690QL. Radi obezbeđenja
Abstract: TIG, welding, dissimilar steels, methods of welded joints testing

\section{OSNOVNI MATERIJAL}

Za izradu čelične konstrukcije koristi se 10025 -6 ), čiji su hemijski sastav i mehaničke konstrukcioni čelik visoke čvrstoće S690QL (EN osobine prikazane u tabelama 1 i 2.

\begin{tabular}{|c|c|c|c|c|c|c|c|c|}
\hline $\begin{array}{c}\text { Oznaka po } \\
\text { EN 10025-6 }\end{array}$ & $\begin{array}{c}\mathbf{C} \\
\max [\%]\end{array}$ & $\begin{array}{c}\mathbf{S i} \\
\max [\%]\end{array}$ & $\begin{array}{c}\mathbf{M n} \\
\max [\%]\end{array}$ & $\begin{array}{c}\mathbf{P} \\
\max [\%]\end{array}$ & $\begin{array}{c}\mathbf{S} \\
\max [\%]\end{array}$ & $\begin{array}{c}\mathbf{N} \\
\max [\%]\end{array}$ & $\begin{array}{c}\mathbf{B} \\
\max [\%]\end{array}$ & $\begin{array}{c}\mathbf{C r} \\
\max [\%]\end{array}$ \\
\hline \multirow{4}{*}{ S690QL } & $\mathbf{0 , 2 0}$ & $\mathbf{0 , 8 0}$ & $\mathbf{1 , 7 0}$ & $\mathbf{0 , 0 2 0}$ & $\mathbf{0 , 0 1 0}$ & $\mathbf{0 , 0 1 5}$ & $\mathbf{0 , 0 0 5 0}$ & $\mathbf{1 , 5 0}$ \\
\cline { 2 - 9 } & $\begin{array}{c}\mathbf{C u} \\
\max [\%]\end{array}$ & $\begin{array}{c}\mathbf{M o} \\
\max [\%]\end{array}$ & $\begin{array}{c}\mathbf{N b} \\
\max [\%]\end{array}$ & $\begin{array}{c}\mathbf{N i} \\
\max [\%]\end{array}$ & $\begin{array}{c}\mathrm{Ti} \\
\max [\%]\end{array}$ & $\begin{array}{c}\mathbf{V} \\
\max [\%]\end{array}$ & $\begin{array}{c}\mathbf{Z r} \\
\max [\%]\end{array}$ & - \\
\cline { 2 - 9 } & $\mathbf{0 , 5 0}$ & $\mathbf{0 , 7 0}$ & $\mathbf{0 , 0 6}$ & $\mathbf{2 , 0}$ & $\mathbf{0 , 0 5}$ & $\mathbf{0 , 1 2}$ & $\mathbf{0 , 1 5}$ & - \\
\hline
\end{tabular}

Tabela broj 1. Hemijski sastav osnovnog materijala

\begin{tabular}{|c|c|c|c|c|c|}
\hline Red. br. & $\begin{array}{c}\text { Oznaka } \\
\text { čelika }\end{array}$ & $\begin{array}{l}\text { Gornji napon } \\
\text { tečenja } R_{e H} \\
\min \left[\mathrm{N} / \mathrm{mm}^{2}\right]\end{array}$ & $\begin{array}{c}\text { Zatezna } \\
\text { čvrstoća } \mathrm{R}_{\mathrm{m}} \\
{\left[\mathrm{N} / \mathrm{mm}^{2}\right]}\end{array}$ & $\begin{array}{c}\text { Izduženje } \\
\mathrm{A}_{5} \\
\min \%\end{array}$ & $\begin{array}{c}\text { Žilavost } \\
\mathrm{KV} \\
\min [\mathrm{J}]\end{array}$ \\
\hline 1. & S690QL & 690 & $770 \div 940$ & 24 & $30\left(-40^{\circ} \mathrm{C}\right)$ \\
\hline
\end{tabular}

Tabela broj 2. Mehaničke osobine

Čelik S690QL (EN 10025 - 6 ) pripada grupi čelika visoke čvrstoće. U principu, svi sitnozrni čelici imaju dobru zavarljivost. Kod kaljenih i otpuštenih sitnozrnih čelika legirajući elementi $\mathrm{Cr}$, $\mathrm{Mn}, \mathrm{Ni}$, Mo snižavaju kritičnu brzinu hlađenja. Pošto se obavlja višeslojno zavarivanje, predgrevanje se izbegava održavanjem dovoljno visoke međuslojne temperature prolaza i korišćenjem odgovarajućeg redosleda zavarivanja, a u skladu sa preporukomSRPS EN1011-2 : $2007 . \quad$ Mogućnost izbegavanja predgrevanja održavanjem visoke međuslojne temperature ne zavisi samo od uslova proizvodnje, već i od hemijskog sastava čelika koji se zavaruje (CET - ekvivalent ugljenika) temperature predgrevanja.

\section{Ekvivalent ugljenika (CET)}

Prema standarda SRPS EN 1011-2 : 2007, uticaj hemijskog sastava na pojavu hladnih prslina okarakterisan je ekvivalentom ugljenika CET $\mathrm{CET}=\mathrm{C} \%+(\mathrm{Mn} \%+\mathrm{Mo} \%) / 10+(\mathrm{Cr} \%+\mathrm{Cu} \%) / 20+$ $\mathrm{Ni} \% / 40$

CET $=0,20+(1,7+0,7) / 10+(1,50+0,50) / 20$ 


\section{Temperatura predgrevanja}

Prema standardu SRPS EN 1011-2:2007; sa slike 1), moguće je odrediti graničnu debljinu lima u zavisnosti od sadržaja legirajućih elemenata i sadržaja vodonika u metalu šava, a u cilju izbegavanja predgrevanja održavanjem međuslojne temperature $100^{\circ} \mathrm{C}$.

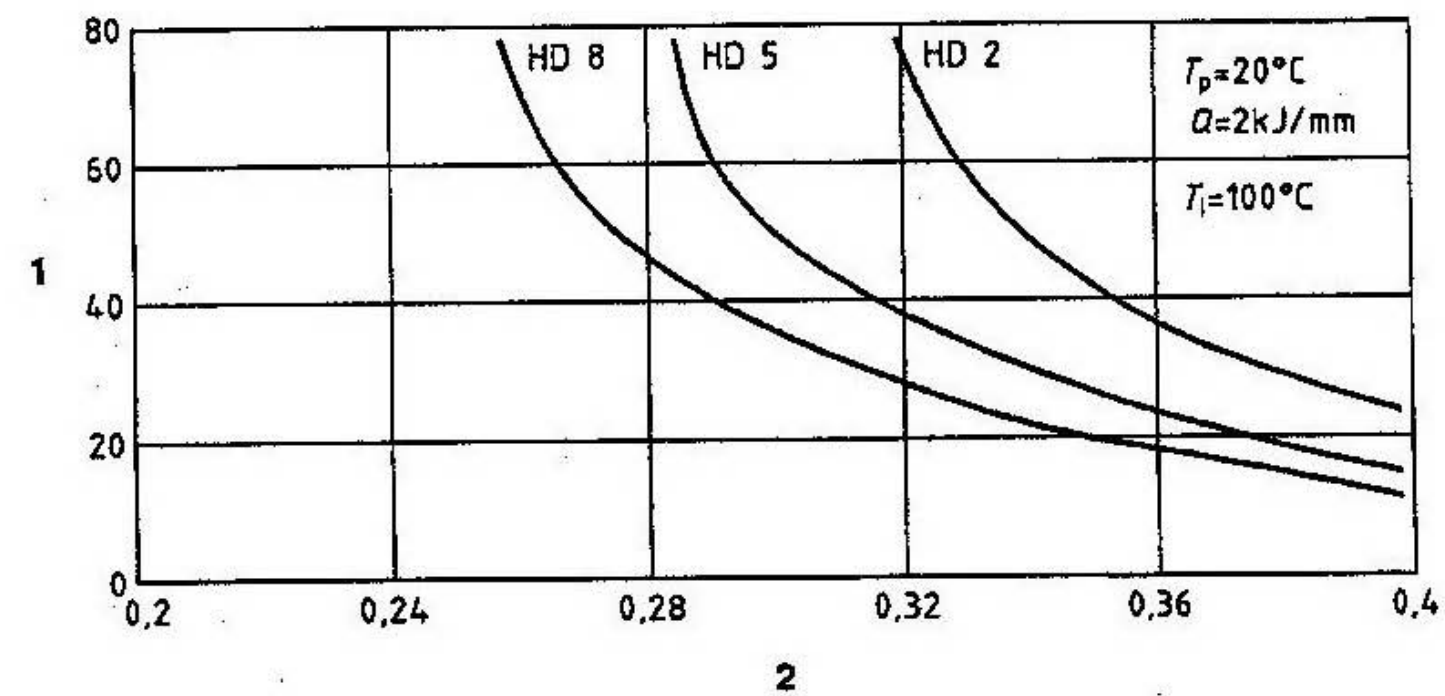

Na slici je:

1 debljina lima $d \mathrm{u} \mathrm{mm}$

2 ekvivalent ugljenika CET u \%

Slika 1) Zavisnost granične debljine lima u zavisnosti od sadržaja legirajućih elemenata i sadržaja vodonika u metalu šava

\section{Sklonost ka pojavi hladnih prslina}

Jedan od pokazatelja povećane krtosti usled fazno-strukturnih promena, a time i sklonosti ka pojavi hladnih prslina, je tvrdoća čelika (HV) u zoni uticaja toplote (ZUT). Smatra se da u slučaju većine konstrukcionih čelika neće doći do formiranja krtih faza ukoliko tvrdoća ne prelazi vrednost $\mathrm{HV}=350$. Na osnovu hemijskog sastava konstrukcijskog čelika i empirijske formule moguće je odrediti vrednosti tvrdoće HV

$\mathrm{HV}=90+1050 \times \mathrm{C}+47 \times \mathrm{Si}+75 \times \mathrm{Mn}+30 \times \mathrm{Ni}+31 \times \mathrm{Cr}$ Zamenom procentualnih masenih sadržaja hemijskih elemenata iz tabele 1

$H V=90+105 \mathrm{C} \times 0,20+47 \times 0,80+75 \times 1,70+30 \times 2,0+31 \times 1,5$

dobija se HV $=571,6>350$

$\mathrm{Na}$ osnovu vrednosti HV, čelik S690QL je sklon pojavi hladnih prslina.

\section{POSTUPAK ZAVARIVANJA}

$\mathrm{Na}$ osnovu podataka o mehaničkim karakteristikama osnovnog materijala, izvođjenja zavarivanja $\mathrm{u}$ hali, kao i na osnovu dimenzija žlebova uslova i mesta zavarivanja, za izvođenje zavarivanja koristiće se postupak MAG (oznaka prema ISO 4063):

135- elektrolučno zavarivanje punom žicom u zaštiti gasa, koji nije inertan.

Sitnozrni čelici se zavaruju svim elektrolučnim postupcima. U odnosu na E postupak, MAG ima prednost zbog jednostavnijeg upravljanja procesom kontrolisanja količine unete toplote preko brzine zavarivanja.Ovo je način da se u ovom slučaju ne primenjuje predgrevanje.

\section{UREĐAJ ZA ZAVARIVANJE}

Za zavarivanje postupkom 135 treba koristiti poluautomate sa mogućnošću regulacije struje u dijapazonu potrebnom za zavarivanje i odgovarajućom intermitencom. Aparati za zavarivanje treba da su provereni i ispravni za rad. Izabran je SAF MIF 400 BLX. 


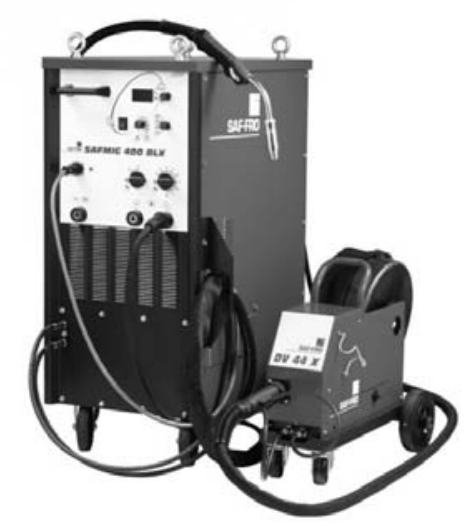

Slika 2) Aparat za zavarivanje SAF MIF 400 BLX.
Napajanje - trofazna naizmenična struja $230 \mathrm{~V} / 400 \mathrm{~V}-50 \mathrm{~Hz}$
Nominalni napon otvorenog strujnog kola. 16,6 do $45,8 \mathrm{~V}$
Struja zavarivanja. 28 do $380 \mathrm{~A}$
Intermitenca na $45 \%$ 380 A $(40 \%)$
Intermitenca na $60 \%$ $320 \mathrm{~A}$
Intermitenca na $100 \%$ $280 \mathrm{~A}$
Dimenzije. $925 \times 580 \times 1060 \mathrm{~mm}$
Masa. $161 \mathrm{~kg}$
Klasa izolacije transformatora $\mathrm{H}$
Klasa zaštite IP 23
Standard EN 60974-1

\section{DODATNI MATERIJAL}

Za zavarivanje postupkom 135 odabrana je žica oznake po AWS 5.18 : ER70S-3. U tabeli 3 data je

uporedna klasifikacija po standardima AWS i EN ISO.

\begin{tabular}{|c|c|c|c|}
\hline Standard & AWS A 5.18 & EN ISO 14341-A & EN 440 \\
\hline Žica & ER70S-3 & G 42 3M21 2Si & G2Si \\
\hline
\end{tabular}

Tabela 3) Klasifikacija žice za MAG postupak 135.

Zavarivanje se vrši u zaštiti mešavine gasova Ferroline C18 (klasifikacija M21 prema EN ISO gasova Ferroline $\mathrm{C} 18 \quad\left(82 \% \mathrm{Ar}+18 \% \mathrm{CO}_{2}\right)$ 14175). Pri zavarivanju u zaštiti mešavine izabrana žica daje metal šava čije su

\begin{tabular}{|c|c|c|c|c|c|c|c|c|}
\hline Žica & $\mathrm{C}[\%]$ & $\mathrm{Si}[\%]$ & $\mathrm{Mn}[\%]$ & $\mathrm{P}[\%]$ & $\mathrm{S}[\%]$ & $\mathrm{Ni}[\%]$ & $\mathrm{Cr}[\%]$ & $\mathrm{Mo[ \% ]}$ \\
\hline \multirow{3}{*}{$\mathrm{G} 423 \mathrm{M} 212 \mathrm{Si}$} & $0,06-0,14$ & $0,50-0,8$ & $0,9-1,3$ & 0,025 & 0,025 & 0,15 & 0,15 & 0,15 \\
\cline { 2 - 9 } & $\mathrm{V}[\%]$ & $\mathrm{Cu}[\%]$ & $\mathrm{Al}[\%]$ & \multicolumn{2}{|c|}{$\mathrm{Ti}+\mathrm{Zr}[\%]$} & - & - & - \\
\cline { 2 - 9 } & 0,03 & 0,35 & 0,02 & \multicolumn{2}{|c|}{0,15} & - & - & - \\
\hline
\end{tabular}

Tabela 4) Hemijski sastav metala čistog šava

\begin{tabular}{|c|c|c|c|c|}
\hline Žica & $\begin{array}{c}\text { Gornji napon tečenja } \\
\mathrm{R}_{\mathrm{eH}} \\
\mathrm{min}\left[\mathrm{N} / \mathrm{mm}^{2}\right]\end{array}$ & $\begin{array}{c}\text { Zatezna čvrstoća } \\
\mathrm{R}_{\mathrm{m}} \\
{\left[\mathrm{N} / \mathrm{mm}^{2}\right]}\end{array}$ & $\begin{array}{c}\text { Izduženje } \\
\mathrm{A}_{5} \\
\mathrm{~min} \%\end{array}$ & $\begin{array}{c}\text { Žilavost } \\
\mathrm{KV} \\
\mathrm{min}[\mathrm{J}]\end{array}$ \\
\hline G 42 3M21 2Si & 420 & $500 \div 640$ & 20 & $80\left(-20^{\circ} \mathrm{C}\right)$ \\
\hline
\end{tabular}

Tabela 5) Mehaničke karakteristike metala čistog šava

Komercijalna oznaka žičane elektrode je : IS-5

G2Si 1.2 B300 16 PLW CO

Proizvođač: ISAF

Prečnik : $\varnothing 1,2(\mathrm{~mm})$ 


\section{PARAMETRI ZAVARIVANJA}

Za zavarivanje koristiti jednosmernu struju obrnute polarnosti. Osnovni parametri zavarivanja dati su tehnološkim listama za oba spoja. Izbor parametra baziran je na preporuci proizvođača dodatnog materijala i podacima iz literature. Za izvođenje zavarivanja koristimo u žicu $\varnothing 1,2 \mathrm{~mm}$.

\begin{tabular}{|l|l|}
\hline Prečnik elektode $\mathrm{d}(\mathrm{mm})$ & $\varnothing 1,2 \mathrm{~mm}$ \\
\hline Napon $(\mathrm{V})$ & $28-30$ \\
\hline Jačina struje $(\mathrm{A})$ & $250-275$ \\
\hline Brzina dodavanja žice $(\mathrm{m} / \mathrm{min})$ & $8,0-10,0$ \\
\hline Protok gasa $(\mathrm{I} / \mathrm{min})$ & 18 \\
\hline
\end{tabular}

Zavarivač pri izboru jačine struje zavarivanja mora imati u vidu da sa većom jačinom struje postiže veći učinak ali su gubici zbog rasprskavanja $\mathrm{i}$ greške u zavaru veće, a kod premalih struja mogu se javiti greške tipa uključaka, nalepljivanja i sl.

\section{PRIPREMA OSNOVNOG MATERIJALA ZA ZAVARIVANJE}

Priprema osnovnog materijala za zavarivanje sastoji se iz gasnog sečenja, mašinske obrade za izradu žljeba odgovarajućeg oblika i dimenzija, prema radioničkoj dokumentaciji i tehnologiji zavarivanja, kao i čišćenja i brušenja.

\section{Priprema pozicija}

Žljebovi se pripremaju mašinski. Dimenzije žljebova su prikazane u tehnološkim listama i rade se u skladu sa standardom EN ISO 9692-1. Čelične površine na kojima se zavaruje moraju biti suve i bez vlage od kondenzacije.

\section{Priprema radnog komada}

Pre početka zavarivanja mora se izvršiti pregled površina koje se zavaruju. One moraju biti metalno čiste (očišćene od vode, ulja, masti, boje, rđe) u širini od $30 \mathrm{~mm}$ sa obe strane žleba.

Elementi koji se spajaju zavarivanjem moraju se dovesti u odgovarajući geometrijski položaj. U ovom slučaju, neophodno je da se sa zavarivanjem počne na tzv. startnim pločicama, sl.3). Time se izbegavaju sve greške, inače tipične, u početku rada npr. pri uspostavljanju luka. Ista tehnika se primenjuje i pri zaustavljanju procesa, tj. na kraju ploča koje se zavaruju.

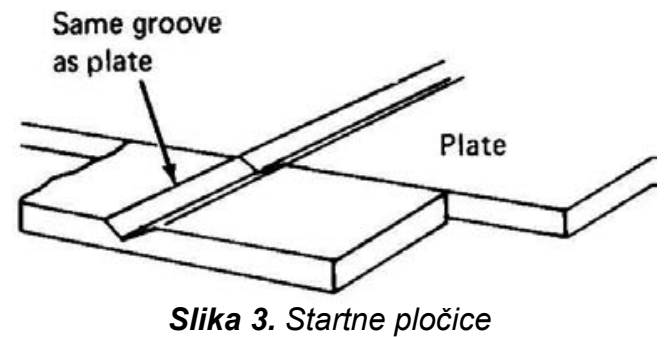

Pripajanje pozicija izvodi se pod istim uslovima zavarivanja kao i koreni prolaz. Pripajanje radnih komada vrše, isključivo, atestirani zavarivači koji su dužni da poštuju sledeće:

1) Svi pripoji moraju biti obrušeni ili pretopljeni.Uspostavljanje luka pri zavarivanju dozvoljeno je samo na startnim pločicama.

2) Kapljice rastopljenog materijala u okolinu zavarenog spoja i prokapine koje nastaju za vreme zavarivanja moraju se obrusiti. Nastavljanje zavara izvoditi nakon obaveznog prethodnog čišćenja već položenog zavara.

\section{Radni uslovi i položaji za izvođenje zavarenog spoja}

Potrebno je obezbediti zaštitu od promaje, zbog zaštitnog gasa. Na radnom mestu ne sme da ima vode. Električni priključci treba da su u ispravnom stanju. Zavarivanje izvoditi u najpovoljnijem položaju (PA) položaju.

\section{PLAN I REDOSLED ZAVARIVANJA}

Površine elemenata u zoni spajanja moraju biti suve i čiste. Postavljanje elemenata u položaj za zavarivanje obavlja se u alatima i uređajima bez pripojnih zavara ili sa pripojnim zavarima u kom slučaju se u toku zavarivanja pripojni zavari moraju odstraniti mehaničkim postupkom žlebljenja.

Prilikom postavljanja elemenata treba voditi računa da zazori po konturi elemenata budu kontinualni po celom obimu.

Zavarivanju se pristupa tek pošto su ispoštovani svi napred navedeni uslovi. Zavarivanje se vrši po pozicijama u skladu sa tehničkom dokumentacijom i sa tehnologijom zavarivanja datom na tehnološkim listovima (WPS) u prilogu.

Redosled zavarivanja je takodje dat $u$ tehnološkom postupku koga se zavarivač mora pridržavati, kako bi se sprečilo unošenje velike količine toplote, koja može negativno da utiče na kvalitet zavarenog spoja. 
Pre sklapanja delovi moraju biti očišćeni od viška Zavarivanje i pripajanje se vrše u PA i PB položaju. masnih naslaga i oksida na svim površinama koji se zavaruju. Potrebno je očistiti ih,odmastiti i izbrusiti.

Rotirati alat svaki put kada je neophodno obezbeditii bolji položaj pri zavarivanju ili pripajanju.

\section{A Šeme redosleda prolaza :}
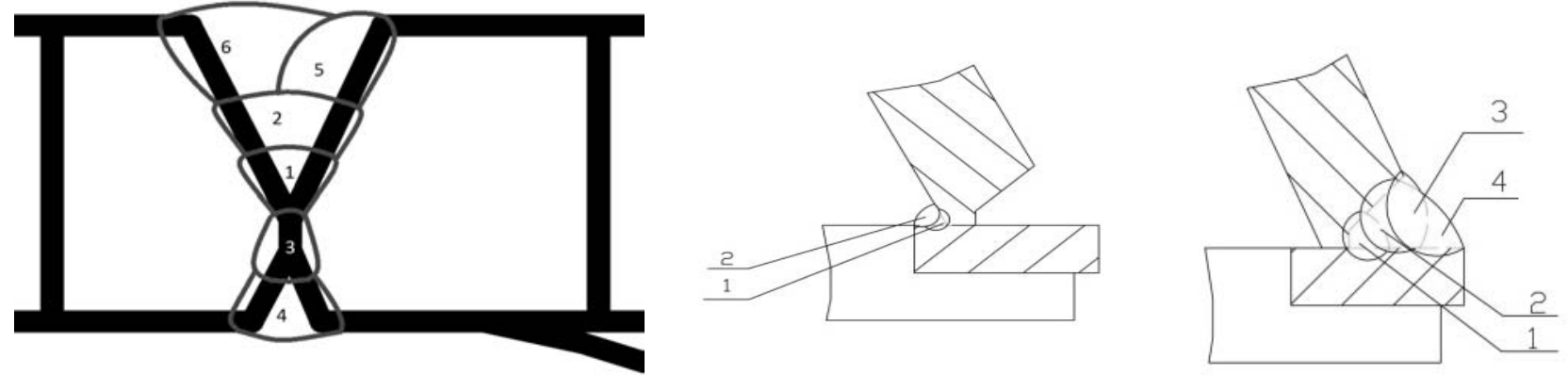

Slika 4) Šeme redosleda zavarivanja

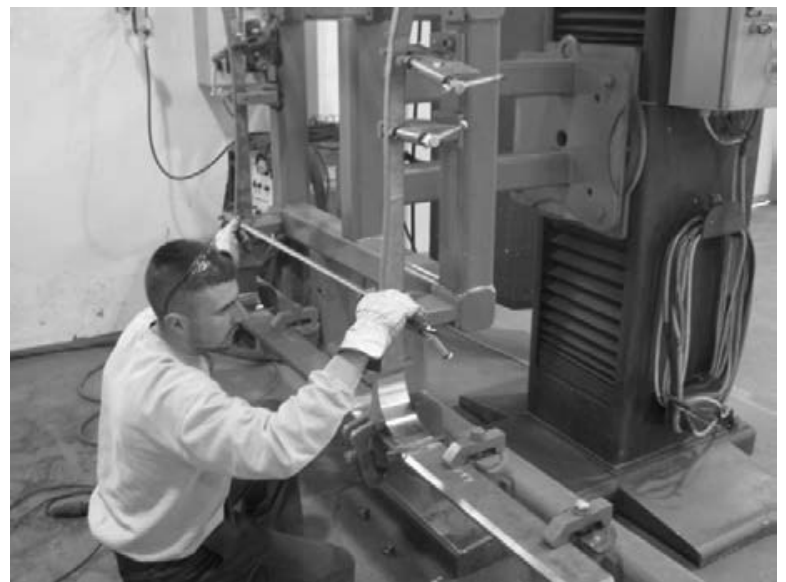

Nakon pritezanja i pripajanja startnih pločica, proveriti sve dimenzije u alatu. Ukoliko su sve mere odgovarajuće, početi zavarivanje u šablonu. Pre zavarivanja potrebno je očistiti žleb koji se zavaruje. Potrebno je podesiti parametre zavarivanja za prvi prolaz i voditi računa da energija bude u zadatim tolerancijama.

Slika 5. Provera dimenzija pre zavarivanja

Zavarivanje izvršiti prema redosledu na slici 11). redosledu zavarivanja i o parametrima zavarivanja Radni komad pritegnuti $u$ alatu. Sve šavove prema WPS za svaki zavar. Vršiti kontrolu pre, za zavariti u horizontalnom položaju. Voditi računa o vreme i posle zavarivanja.

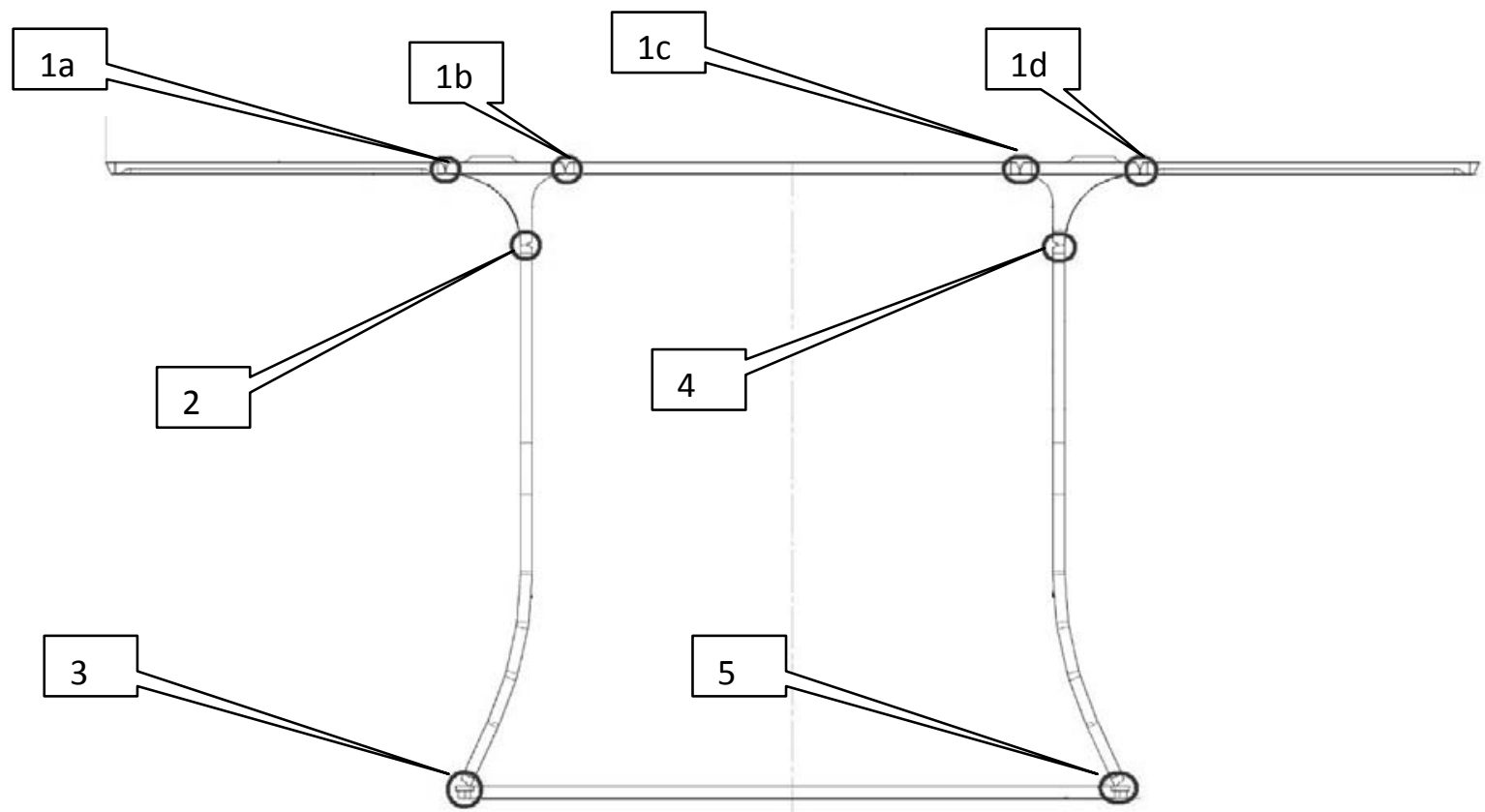

Slika 6. Redosled zavarivanja 


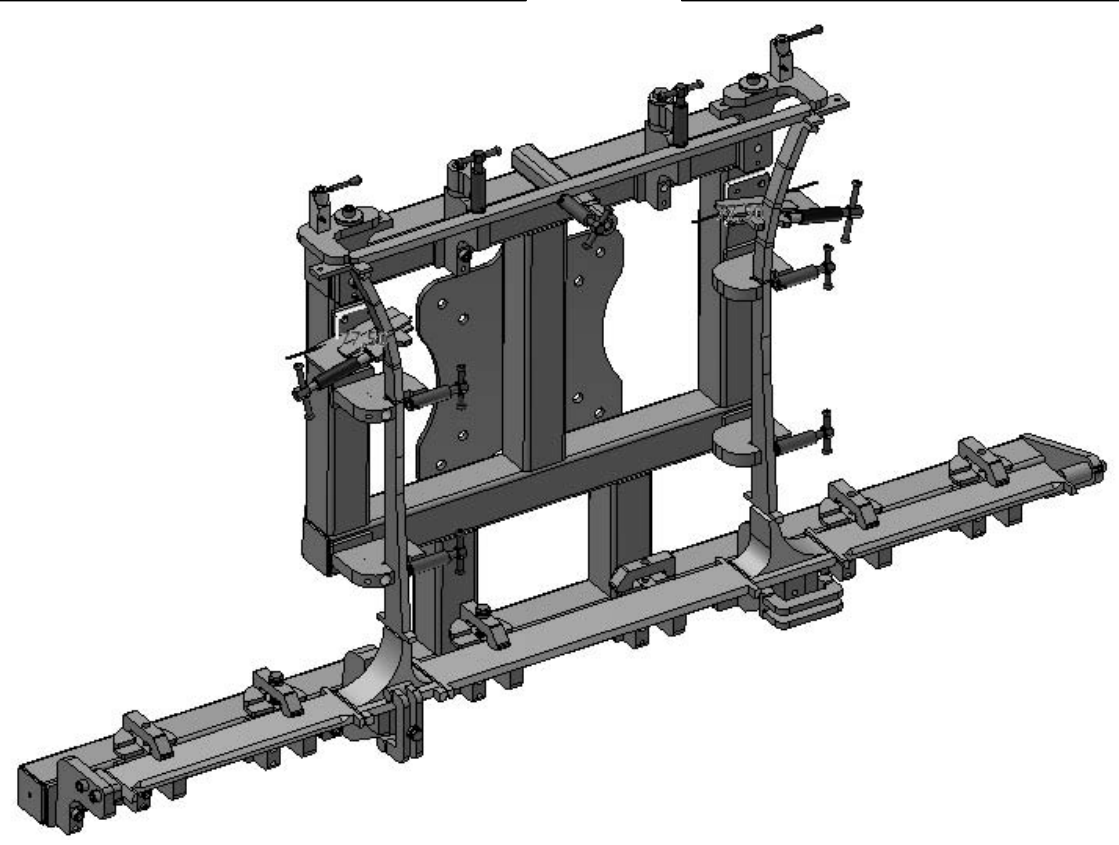

Slika 7. Traverza u alatu za zavarivanje

Kontrola kvaliteta izrade zavarenih spojeva krovne čelične konstrukcije i zavarivanja pri sklapanju iste se izvodi kroz 3 faze:
○ Kontrola pre zavarivanja
- Kontrola u toku zavarivanja
O Kontrola posle zavarivanja

\section{Kontrola pre zavarivanja obuhvata sledeće aktivnosti:}

- Geometrije elemenata za ugradnju;

- Čišćenja delova u zoni zavarenog spoja;

- Funkcionalnosti aparata za zavarivanje;

- Provera protoka zaštitnog gasa;

- Provera žice za zavarivanje;

- Geometriju žlebova za zavarivanje;

- Sertifikate potrošnog materijala;

- Sertifikate zavarivača;

\section{Kontrola u toku zavarivanja}

Provera primene propisanih elemenata tehnologije

- Propisane parametre zavarivanja;

- Brušenje radi čošćenja nakon svakog prolaza;

- Pridržavanje potrebnog redosleda zavarivanja;

- Čišćenje prethodno izvedenih zavarenih spojeva;

\section{Kontrola nakon zavarivanja}

Posle zavarivanja izvršiti sledeću kontrolu spojeva u skladu sa standardom EN 1090:

- Vizuelni kontrolu zavarenih spojeva u obimu $100 \%$;
- Geometrijsku kontrolu svih šavova i elemenata koji se spajaju zavarivanjem, u obimu $100 \%$; Kontrola ultrazvukom (UT) svih sučeonih zavarenih spojeva, prema zahtevu kupca.

Kriterijum prihvatljivosti grešaka u zavarenim spojevima prema standardu EN ISO 5817 odnosno EN 15085 prema CPC2 i CPC3 kvalitetu zavarenih spojeva. O izvršenoj kontroli prikupiti izveštaje.

\section{Popravka grešaka nakon zavarivanja}

Nedopustive greške nastale pri zavarivanju moraju se popraviti. U tom smislu merodavan je kriterijum prihvatljivosti prema EN 15085. Ponovno zavarivanje radi popravljanja se vrši prema WPS listi za popravljani zavar.

\section{Spisak korišćenih standarda}

EN 15085 Zavarivanje željezničkih vozila i komponenti

SRPS ISO 5817 - Kriterijumi prihvatljivosti grešaka zavarenih spojeva

SRPS ISO 6520 - Klasifikacija grešaka u zavarenim spojevima izvedenim topljenjem metala

SRPS ISO 9692 - Zavarivanje- Oblici i mere zlebova za elektrolučno zavarivanje

ISO 9606-1 Kvalifikacija zavarivača i čeličnih materijala

\section{Literatura}

1) Vlastimir Palić - Zavarivanje, Novi Sad 1987.

2) Grupa autora - Predavanje sa kursa za IWE

Nenad Kokeza - Diplomski rad, Projektovanje tehnologije izrade sapnice, Novi Sad 2001 